\title{
Seasonal evolution impact on Montepulciano grape ripening
}

\author{
Vania Lanari $^{1 *}$, Filippo Maria Zacconi ${ }^{1}$, Saverio Illuminati ${ }^{2}$, Lorenzo Gigli ${ }^{2}$, Gianfranco Canullo ${ }^{2}$, Tania Lattanzi $^{1}$, \\ Edoardo Dottori ${ }^{1}$, and Oriana Silvestroni ${ }^{1}$ \\ ${ }^{1}$ Dipartimento di Scienze Agrarie, Ambientali ed Alimentari, D3A, Via Brecce Bianche 10, 60131 Ancona, Italy \\ ${ }^{2}$ Azienda vitivinicola Conti degli Azzoni, Via Don Minzoni 26, 62010 Montefano (MC), Italy
}

\begin{abstract}
In an environmental background characterized by climate change, the seasonal trend increasingly affects the qualitative and quantitative expression of the vineyards. The sugar concentration, titratable acidity, the ratio sugar/acids and yield were related with heat accumulation (growing degree days accumulation), calculated in different period of grapevine cycle. The $21.5^{\circ} \mathrm{Babo}$ threshold has been reached by Montepulciano grapes in the various years (2007-2019) even with 40 days difference. Over a period of 13 years, the sugar of Montepulciano grapes was influenced by thermal evolution between March to July. The relationship with high coefficient determination $\left(\mathrm{R}^{2} 0.74\right)$ was obtained between heat accumulation and titratable acidity. According to this forecasting model, increases in heat accumulation of 100 degree-days in the period from March to June correspond to a reduction of about $0.85 \mathrm{~g} / \mathrm{l}$ of acidity of the must at the harvest associated with an increase of 0.75 degree-days in the ratio between sugars and acids. The thermal evolution between June and July was correlated with yield of Montepulciano, an increase of 100 degree-days is associated with a decrease of about $1.86 \mathrm{t} / \mathrm{ha}$. The thermal evolution between March and July is crucial for yield and grape quality of Montepulciano.
\end{abstract}

\section{Introduction}

It is well known that the thermal increase, due to global warming, is anticipating grapevine phenology (budburst, anthesis, veraison) and accelerating grape ripening, leading to excessive sugar accumulation in berries and therefore high alcohol concentration in the resultant wines [1]. This climatic condition has induced a change in vineyard management techniques $[2,3,4]$, but it is also well known that the grapevine cycle is strongly influenced by the thermal seasonal trend, as shown by the close correlation between bioclimatic indexes and phenological phases [5]. In Central Italy from 1974 to 2013, the relationship with bioclimatic indices, showed that the temperatures during the months March to June, corresponding to vegetative growth, influence the harvest date in Montepulciano vines [6]. Summer temperature, from July to September, corresponding to the berry ripening period, did not influence the grape harvest date but the grape sugar concentration [7].

In the present situation of climate change and wide variability in seasonal trend, the use of prediction models is becoming increasingly important and needs to be calibrated in different environments and on different cultivars. Although it is widely accepted that temperature and precipitation are the main environmental factors regulating phenological timing and growth rates in plants [8], the seasonal thermal trend influences the grape ripening evolution, harvest date, yield and grape quality, and there is still a lack of knowledge on the relevance of these relationships. This study aims at their quantification and their possible use in a forecast model.

\section{Materials and Methods}

The data related to harvest date, must composition and yield of Montepulciano, were provided by the Cantina Conti degli Azzoni di Montefano (MC, Marche) for the period 2007-2019. The vineyard was planted in 1968 and extends for about 2.8 ha, on a hilly side facing south, with a $25 \%$ slope at an altitude of $140 \mathrm{~m}$ asl.

Montepulciano vines, cordon trained, and vertical shoot positioned on bilateral guyot systems, were distant $1.4 \mathrm{~m}$ on the row and $3 \mathrm{~m}$ between the rows. The rows are north-south oriented. The soil was managed with perennial cover-crop, controlled only with mowing in spring and late summer.

Daily meteorological data were obtained from the Regional Hydrographic Service (Protezione Civile della Regione Marche). The daily mean temperature values, during the 2007-2019 period, were used to calculate heat accumulation (degree-days accumulation, considering the thermal threshold at $10{ }^{\circ} \mathrm{C}$ ) in different period of grapevine annual cycle. The heat accumulation was used to describe the relationship with harvest date (considering grape harvest at $21.5^{\circ} \mathrm{Babo}$ ), yield and grape quality.

\footnotetext{
*Corresponding author: v.lanari@staff.univpm.it
} 


\section{Results and Discussion}

The yearly seasonal trend of the 2007-2013 period were different, even between consecutive years (Fig. 1) influencing grape ripening in different way. In the period 2007-2019, the wettest year was 2010, with 1034 $\mathrm{mm}$ of rainfall, with low temperatures, followed as to rainfall by years 2014 and 2013 (Fig. 1).

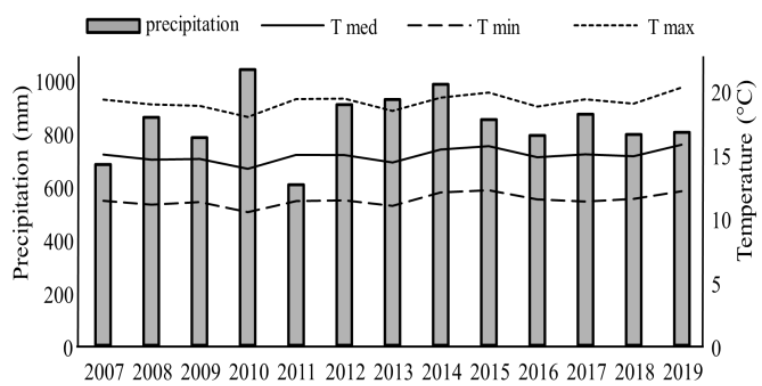

Figure 1. Annual temperature and precipitation trend in the period 2007-2019 in the area under observation

On the contrary, the seasonal trend of 2011 was the driest, with low rainfall during the summer months (about $56 \mathrm{~mm}$ ) which fell during the bunch development and ripening.

The 13-year average heat accumulation for the vineyard under study in the period 1 April-31 October [9], corresponding to the whole vine cycle, summed 2036 degree-days (Tab. 1).

Compared to the period average, years with higher heat accumulations were 2011, 2012 and 2015 characterized by values of 2167, 2177 and 2152 degreedays, respectively. These years are among the driest of the period considered. Then, in some years such as 2010 and 2014, rather low degree-day values of 1839 and 1840, respectively were recorded (Tab. 1), characterizing these years as cooler and wet.

The heat accumulation was calculated for each year, in the two periods March-June and July-September, in some viticultural areas of the Abruzzo region [5].

In the period March to June, corresponding to canopy vegetative development, the average heat accumulation was 723 degree-days. In the 2008, 2010, 2013, 2014 and 2016 seasons, heat accumulation was between a minimum of 621 degree-days in the wet 2013 season, and a maximum of 841 degree-days in 2007 (Tab. 1). For the period July to September, corresponding to berry ripening, the average value of heat accumulation in the 13 years was 1194 degree-days. The years 2011, 2012 and 2015 with the respective heat accumulation values of 1289,1292 and 1287 degreedays were the warmest seasons, while 2010 and 2014 with 1118 and 1014 degree-days were registered as the coldest (Tab. 1).

The curves of the grape ripening, provided by the winery, allowed to analyze the evolution of sugar accumulation in the berry (Fig. 2).
Table 1: Heat accumulation calculated in the periods 1 April31 October, 1 March-30 June and 1 July-30 September, in the area under observation for the period 2007-2019.

\begin{tabular}{|c|c|c|c|}
\hline & $\begin{array}{c}\boldsymbol{\Sigma} \text { April- } \\
\text { October }\end{array}$ & $\begin{array}{c}\boldsymbol{\Sigma} \text { March - } \\
\text { June }\end{array}$ & $\begin{array}{c}\boldsymbol{\Sigma} \text { July - } \\
\text { September }\end{array}$ \\
\hline $\mathbf{2 0 0 7}$ & 2058 & 841 & 1141 \\
\hline $\mathbf{2 0 0 8}$ & 1996 & 693 & 1150 \\
\hline $\mathbf{2 0 0 9}$ & 2062 & 720 & 1223 \\
\hline $\mathbf{2 0 1 0}$ & 1839 & 652 & 1118 \\
\hline $\mathbf{2 0 1 1}$ & 2167 & 759 & 1289 \\
\hline $\mathbf{2 0 1 2}$ & 2177 & 781 & 1292 \\
\hline $\mathbf{2 0 1 3}$ & 1947 & 621 & 1174 \\
\hline $\mathbf{2 0 1 4}$ & 1840 & 679 & 1014 \\
\hline $\mathbf{2 0 1 5}$ & 2152 & 752 & 1287 \\
\hline $\mathbf{2 0 1 6}$ & 1920 & 642 & 1168 \\
\hline $\mathbf{2 0 1 7}$ & 2133 & 808 & 1223 \\
\hline $\mathbf{2 0 1 8}$ & 2135 & 763 & 1218 \\
\hline $\mathbf{2 0 1 9}$ & 2038 & 685 & 1223 \\
\hline $\mathbf{A v e r a g e}$ & 2036 & 723 & 1194 \\
\hline
\end{tabular}

Montepulciano grapes reached the threshold of 21.5 ${ }^{\circ} \mathrm{Babo}$ between the beginning and mid-September in the hottest and driest years (2007, 2011 and 2017), while in the wettest years $(2013,2014$ and 2018) the threshold of $21.5^{\circ}$ Babo was reached at least 40 days later. In the considered period (2007-2019) the earliest harvest was carried out in 2011 , on 5 October (66 days from $1^{\circ}$ august), when the grapes had reached $23.45{ }^{\circ}$ Babo, while the later one in 2013 , on 28 October ( 89 days from $1^{\circ}$ august), with sugar concentration in grapes reaching $23{ }^{\circ}$ Babo (Fig. 2). The hottest years registered an increase in sugar concentration, as happened for 2008, where the highest sugar concentrations of $24^{\circ} \mathrm{Babo}$ was reached, but also in 2011 and 2015 season when grape showed values of 23.45 and $23.0{ }^{\circ}$ Babo, respectively (Fig. 2). In humid and cool seasons such as 2014, it can be observed that sugars on 1 September had not reached $20{ }^{\circ}$ Babo yet and, considering the actual harvest date, we may observe that berries were characterized by the lowest sugar content of $20.35^{\circ}$ Babo in the whole 20072019 period (Fig. 2).

The correlation between heat accumulation in the first period of the vine cycle, from March till July and the achievement of sugar accumulation at $21.5^{\circ} \mathrm{Babo}$, revealed a determination coefficient value $\left(R^{2}\right)$ of 0.45 . 


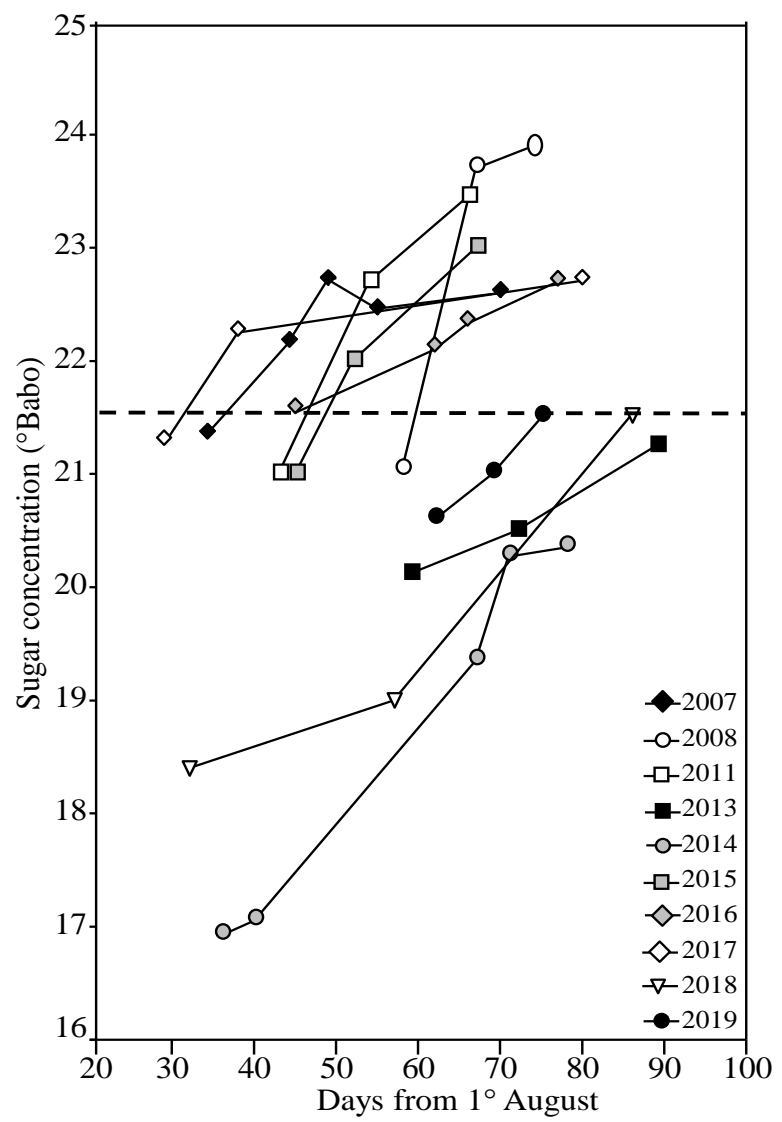

Figure 2. Seasonal trend of Montepulciano sugar concentration in the period 2007-2019. The horizontal dotted line indicates the $21.5^{\circ} \mathrm{Babo}$ threshold.

The negative slope coefficients show that the increase in these indices corresponds to an earlier date when the grapes reached the threshold of $21.5{ }^{\circ}$ Babo. Therefore, increases in heat accumulation of 100 degree-days in the period March-July, led to anticipation of about 14 days in achievement of $21.5^{\circ}$ Babo (Fig. 3).

The heat accumulation from March to June and titratable acidity trend, showed a close relationship, as well as heat accumulation and a sugar/ acids ratio evaluated at harvest, as shown by the high values of $\mathrm{R}^{2}$ of 0.74 and 0.71 respectively (Fig. 4). Increases of 100 degree-days in the period March-June resulted in a loss of about $0.85 \mathrm{~g} / \mathrm{l}$ of titratable acidity in the must at harvest and a corresponding increase of about 0.75 degree-days in the sugar/acids ratio.

Observing the relationship between grape yield and heat accumulation in the months June-July, an $\mathrm{R}^{2}$ of 0.32 is obtained and a decreasing slope is revealed (Fig. 5), suggesting that the yield decreased by $1.86 \mathrm{t} / \mathrm{ha}$ with increasing temperatures in June and July (for increments of 100 degree-days) with low significance.

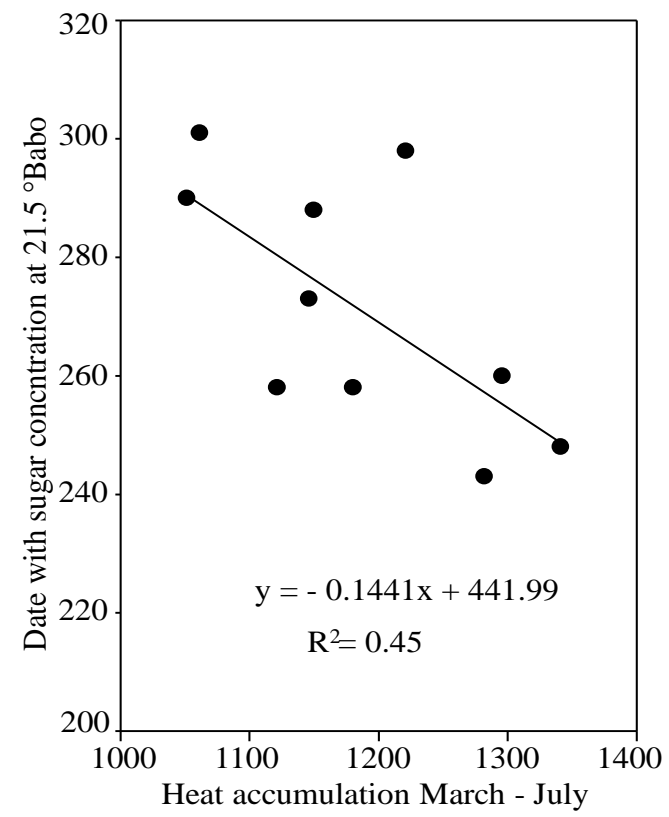

Figure 3. Relationship between the date (days from 1 January) in which the Montepulciano grapes reached a sugar concentration of $21.5^{\circ} \mathrm{Babo}$ and the thermal accumulation from March to July in the period 2007-2019.

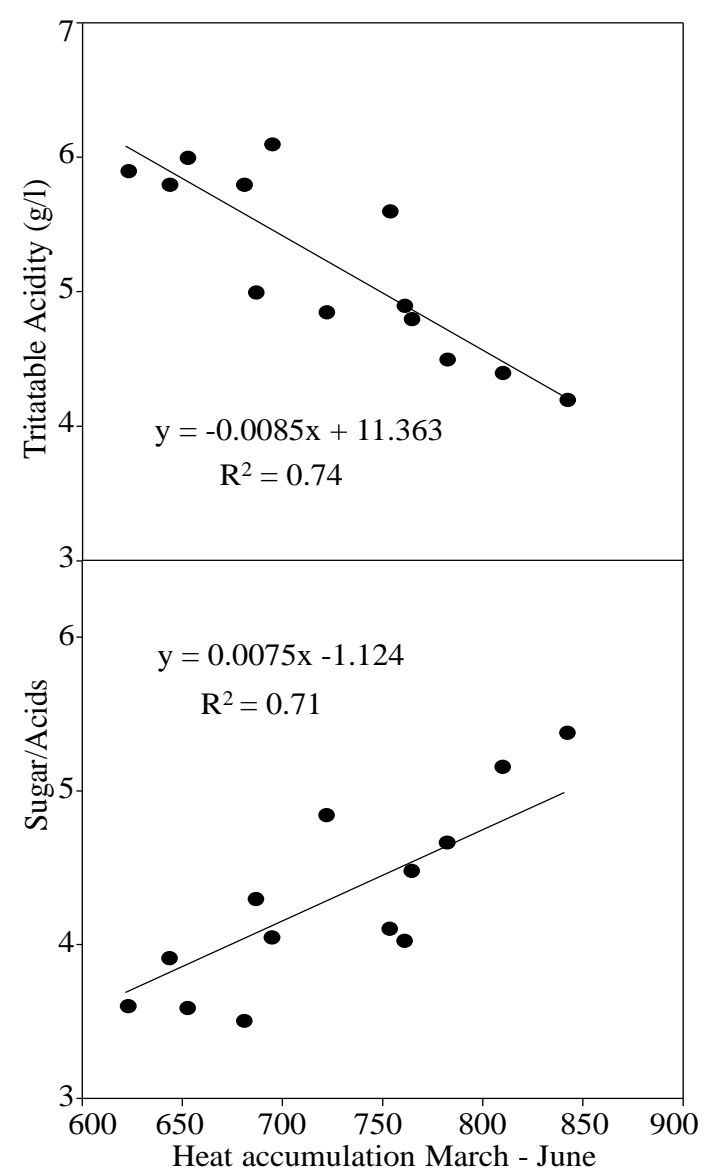

Figure 4. Relation between acidity and sugar/acids ratio of Montepulciano grapes at harvest and heat accumulation from March to June in the period 2007-2019. 


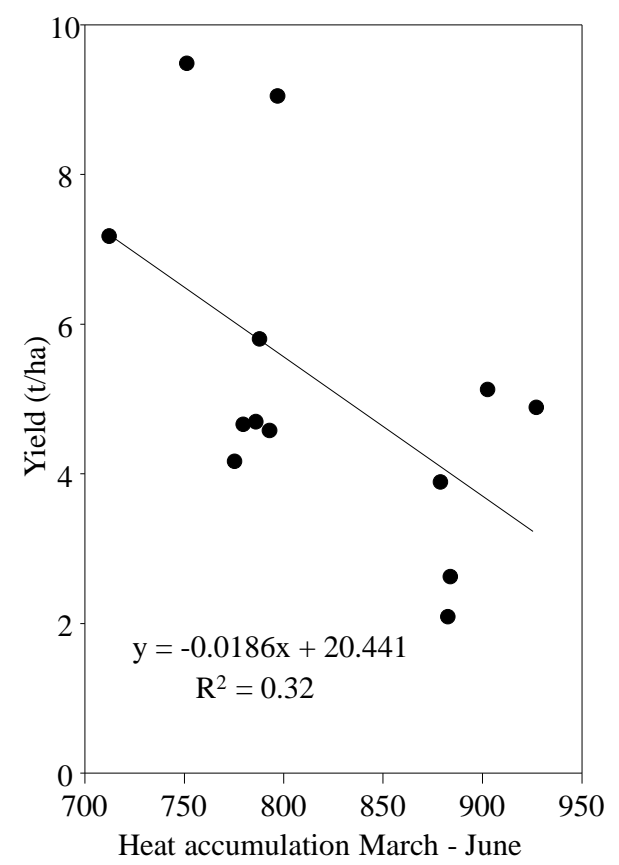

Figure 5. Relationship between Montepulciano grapes yield and heat accumulation from June to July in the period 20072019.

\section{Conclusions}

This study confirms that the seasonal trend affects the vine cycle: the thermal trend during the first phase of annual vine cycle, from March to July, is crucial for grape ripening, must composition at harvest and the yield.

The forecast models considering must composition and yield on Montepulciano for 13 years, could also be useful to define vineyard management strategies useful to cope with changing climatic conditions underway.

An important thermal accumulation between March and June can be considered a sign of a probably early and not very abundant harvest, therefore in June we could intervene with strategies capable of slowing down and improvement the grape quality, such as the use of antitranspirants, powders with shielding effect (kaolin and zeolite), shading nets application or canopy management practices, capable of limiting solar radiation on the bunches (avoiding drastic topping and/or defoliation in yield zone)

\section{References}

1. G.V. Jones, M.A. White, O.R. Cooper, K. Storchmann. Climate Change 73, 319-343 (2005).

2. A. Palliotti, S. Tombesi, O. Silvestroni, V. Lanari, M. Gatti, S. Poni. Sci Hortic. 178, 4354 (2014)

3. O. Silvestroni, V. Lanari, T. Lattanzi, E. Dottori and A. Palliotti. Australian Journal of Grape and Wine Research 26, 363-371 (2020)
4. V. Lanari, T. Lattanzi, B. Di Lena, A. Palliotti, O. Silvestroni. BIO Web of Conferences 13, 04001 (2019)

5. O. Silvestroni, V. Lanari, T. Lattanzi, A. Palliotti. Austr. J. Grape and Wine Res. 24, 478-486 (2018)

6. B. Di Lena, O. Silvestroni, V. Lanari, A. Palliotti. Theore. and App. Climat., 136, 1145 1155 (2019).

7. V. Lanari, A. Palliotti, P. Sabbatini, G.S. Howell, O. Silvestroni, O. Scientia Horticulturae 179, 239-247 (2014)

8. O. Silvestroni, A. Palliotti, B. Di Lena, V. Nuzzo, P. Sabbatini, T. Lattanzi, V. Lanari. Acta Physiologiae Plantarum 42, 147-159 (2020)

9. M.A. Amerine, A.J. Winkler Hilgardia 15, 493-675 (1944) 